\title{
Synthesis and Properties of Arylacetylene Resins with Siloxane Units
}

\author{
Fei Gao, Lingling Zhang, Lemin Tang, Jian Zhang, Yan Zhou, Farong Huang, ${ }^{*}$ and Lei Du
}

\author{
Key Laboratory for Specially Functional Polymeric Materials and Related Technology of the Ministry of Education, \\ School of Materials Science and Engineering, East China University of Science and Technology, 130 Meilong Road, \\ Shanghai 200237, China. E-mail: fhuanglab@ecust.edu.cn \\ Received October 23, 2009, Accepted December 15, 2009
}

\begin{abstract}
A series of arylacetylene resins with siloxane units were synthesized by the condensation reactions of $m$-diethynylbenzene magnesium reagents with various $\alpha, \omega$-bis(chloro)dimethylsiloxanes. These resins are liquids and are miscible with common organic solvents at room temperature. The structures of the resins were characterized by FT-IR, ${ }^{1} \mathrm{H}$ NMR, ${ }^{13} \mathrm{C} \mathrm{NMR},{ }^{29} \mathrm{Si} \mathrm{NMR}$, and gel permeation chromatography (GPC). The thermal behaviors of the resins were examined with differential scanning calorimetry (DSC). These resins have good processability. They can be thermally crosslinked through the ethynyl groups to produce cured resins. The thermal and thermooxidative stabilities of the cured resins were studied by thermogravimetric analysis (TGA). The cured resins possess high thermal and thermooxidative stability. Their decomposition occurs at above $500^{\circ} \mathrm{C}$ in both $\mathrm{N}_{2}$ and air. With increasing the length of siloxane units in the resins, the thermal stability of the cured resins decreases in $\mathrm{N}_{2}$. When the cured resins were sintered above $1450{ }^{\circ} \mathrm{C}$ under argon, hard and glassy SiOC ceramics were obtained. These SiOC ceramics have the decomposition temperatures at $5 \%$ weight loss above $800{ }^{\circ} \mathrm{C}$ in air.
\end{abstract}

Key Words: Arylacetylene resin with siloxane units, Diethynylbenzene, Siloxane, Organic-inorganic polymer, Ceramic

\section{Introduction}

Polyarylacetylene (PAA) was first synthesized by Hay and co-workers as a family of high-temperature polymers. ${ }^{1-3}$ PAA is a prepolymer or oligomer, which is derived from diethynylbenzene and possesses excellent properties such as low dielectric constant, low moisture pickup, and high thermal stability. Unfortunately, PAA suffers from problems such as poor process control, low mechanical properties, and the susceptibility to decomposition at elevated temperatures in oxidative environments.

To improve the processability, mechanical properties, and thermooxidative stability, more attention has been focused on the modifications of PAA. ${ }^{4-13}$ Itoh and coworkers have developed a silicon-containing polyarylacetylene. ${ }^{4}$ The siliconcontaining polyarylacetylene, poly[(phenylsilyleneethynylene1,3-phenyleneethynylene)] (named MSP), was synthesized by dehydrogenative coupling polymerization reactions between phenylsilane and $m$-diethynylbenzene. The cured MSP possesses high decomposition temperature and high residue yield at $1000{ }^{\circ} \mathrm{C}$. Several reports concerning MSP have been published. The potential applications of the MSP materials are considered as composite materials, ceramic materials, and electronic materials. $^{4-7}$ In 2001, phenylacetylene terminated poly(silyleneethynylenephenyleneethynylene) oligomers abbreviated as BLJ were synthesized by the condensation reaction between dichlorosilane and a mixture of diethynylbenzene and phenyl acetylene magnesium reagents. ${ }^{8}$ This BLJ resin is an easily processable polymer and cured at elevated temperature to form a crosslinked polymer with high heat resistance and high char yield.

It is well known that siloxane-containing polymers possess some unique properties, including good flexibility, high heat resistance, excellent moisture resistance, and good electrical properties. ${ }^{14,15}$ Recently, several investigations have been conducted on polymers containing siloxane and acetylene units. ${ }^{16-24}$ For example, Keller ${ }^{17}$ and coworkers reported the preparation of linear siloxane-diacetylene polymers by reacting dichlorosiloxanes with dilithiodiacetylene. These linear silxoane-diacetylene polymers show excellent thermal and thermooxidative stabilities. Beckham ${ }^{21}$ and coworkers have also reported the synthesis of diacetylene-containing poly(dimethylsiloxane)s. However, there are few reports on the incorporation of dimethylsiloxane units into the polyarylacetylene backbone. ${ }^{25,26}$

In this report, we have designed and prepared a series of arylacetylene resins with various dimethylsiloxane unit lengths. The resins were characterized by FT-IR, NMR, GPC, DSC, and TGA techniques. The relationship between the structures and properties of the resins was investigated.

\section{Experimental}

Materials. Unless otherwise noted, all syntheses were performed under an atmosphere of dry nitrogen. Hexane, tetrahydrofuran (THF), carbon tetrachloride $\left(\mathrm{CCl}_{4}\right)$, ethyl bromide (EtBr), ethyl ether, dimethyldichlorosilane, palladium dichloride $\left(\mathrm{PdCl}_{2}\right)$, silica gel, magnesium powder, and phosphorus pentoxide $\left(\mathrm{P}_{2} \mathrm{O}_{5}\right)$ were purchased from Sinopharm Chemical Reagent Co. Ltd. Tetrahydrofuran (THF) was refluxed over sodium with benzophenone and freshly distilled in nitrogen before use. Carbon tetrachloride $\left(\mathrm{CCl}_{4}\right)$ was distilled over $\mathrm{P}_{2} \mathrm{O}_{5}$. Dimethyldichlorosilane and ethyl bromide were distilled before use. Dimethylchlorosilane and 1,1,3,3-tetramethyldisiloxane (TMDS) were purchased from Shanghai Sili Gongmao Co. Ltd. and used as received. Octamethylcyclotetrasiloxane $\left(\mathrm{D}_{4}\right)$ was purchased from Shanghai Hua Run Chemicals Co. Ltd. and used 
as received. 1,1,3,3,5,5-Hexamethyltrisiloxane (HMTS), 1,3dihydroxytetramethyldisiloxane (DHTMDS), 1,1,3,3,5,5,7,7Octamethyltetrasiloxane (OMTS), 1,1,3,3,5,5,7,7,9,9,11,11dodecamethylhexasiloxane (DMHS), 1,3-dichlorotetramethyldisiloxane (DCTMDS), 1,5-dichlorohexamethyltrisiloxane (DCHMTS), 1,7-dichloroocta methyltetrasiloxane (DCOMTS), and 1,11-dichlorododecamethylhexasiloxane (DCDMHS) were synthesized according to procedures described in the literatures. ${ }^{27-32}$ $m$-Diethynylbenzene was supplied by Fine Chemical Institute of East China University of Science and Technology and used as received.

Characterization. ${ }^{1} \mathrm{H} \mathrm{NMR},{ }^{13} \mathrm{C} \mathrm{NMR}$, and ${ }^{29} \mathrm{Si} \mathrm{NMR}$ spectra were performed on a BRUKER AVANCE $500(500 \mathrm{Mz})$ instrument, using teramethylsilane (TMS) as an external standard in a $\mathrm{CDCl}_{3}$ solution. Fourier transform infrared (FT-IR) spectra were obtained using a Nicolet 550 spectrometer. The molecular weights of the resins were determined by gel permeation chromatography (GPC) using a Waters GPC system equipped with a DAWN HELEOS static laser scattering detector and an Optilab Rex refractive index detector. GPC was performed using THF as an eluent at a flow rate of $1 \mathrm{~mL} / \mathrm{min}$. Differential scanning calorimetric analyses (DSC) were performed on a NETZSCH $200 \mathrm{PC}$ module at the heating rate of $10{ }^{\circ} \mathrm{C} / \mathrm{min}$ under nitrogen. Thermogravimetric analyses (TGA) were performed on a TA Instruments SDT Q600 analyzer. All thermal analyses were performed at the heating rate of $10^{\circ} \mathrm{C} / \mathrm{min}$ under nitrogen or air with the flow rate of $15 \mathrm{~cm}^{3} / \mathrm{min}$. XRD spectrum was obtained on a Rigaku (Japan) D/max $2550 \mathrm{VB} / \mathrm{PC}$ diffractometer.

Synthesis of arylacetylene resins with siloxane units. A 250 $\mathrm{mL}$ roundbottomed flask was equipped with a dropping funnel, a reflux condenser, a three-way stopcock, and a mechanical stirring bar. The flask was then evacuated and back-filled three times with dry nitrogen. Magnesium powder $(6.00 \mathrm{~g}, 0.25 \mathrm{~mol})$ and anhydrous THF $(100 \mathrm{~mL})$ were transferred into the flask. The reaction flask was then immersed in an ice/water bath. While stirring, a solution of ethyl bromide $(23.98 \mathrm{~g}, 0.22 \mathrm{~mol})$ in 100 $\mathrm{mL}$ anhydrous THF was added dropwise over $40 \mathrm{~min}$, forming a gray black solution. The ice/water bath was removed and the reaction mixture was heated to $45^{\circ} \mathrm{C}$ with an oil bath with stirring over $1 \mathrm{~h}$, resulting in the formation of a dark solution. The reaction flask was then cooled with an ice/water bath and a solution of $m$-diethynylbenzene $(13.86 \mathrm{~g}, 0.11 \mathrm{~mol})$ in anhydrous THF $(100 \mathrm{~mL})$ was added dropwise over $40 \mathrm{~min}$. After complete addition, the ice/water bath was removed and the reaction mixture was heated to $65^{\circ} \mathrm{C}$ with an oil bath with stirring over $1 \mathrm{~h}$. The reaction mixture was thick slurry with a white precipitate. The flask was then cooled with an ice/water bath and a solution of DCTMDS (14.21 g, $0.07 \mathrm{~mol})$ in anhydrous THF (100 mL) was added dropwise over $40 \mathrm{~min}$. As the addition proceeded, the white precipitate of the organic magnesium reagent gradually disappeared. After complete addition, the ice/water bath was removed and the reaction mixture was heated to $75{ }^{\circ} \mathrm{C}$ with an oil bath. The reaction was allowed to proceed overnight at $75^{\circ} \mathrm{C}$. After cooling to room temperature, the reaction mixture was then poured into a $2 \%$ solution of hydrochloric acid $(300 \mathrm{~mL}$, aqueous) at $0{ }^{\circ} \mathrm{C}$. The resulting two-phase mixture was transferred to a $500-\mathrm{mL}$ separatory funnel and extracted three times with $75 \mathrm{~mL}$ each of toluene. The toluene extracts were combined and washed with deionized water until $\mathrm{pH}$ of the washed water was neutral. The dark organic phase was poured into a roundbottomed flask and dried over anhydrous $\mathrm{Na}_{2} \mathrm{SO}_{4}$. Filtration into a roundbottomed flask was followed by rotary evaporation and then exposure to reduced pressure at room temperature for $5 \mathrm{~h}$. The resin I was obtained in 93\% yield as a brown viscous liquid. FTIR $\left(\mathrm{KBr}, \mathrm{cm}^{-1}\right) 3297(\mathrm{C} \equiv \mathrm{C}-\mathrm{H}), 3068(\mathrm{Ar}-\mathrm{H}), 2962$ $\left(-\mathrm{CH}_{3}\right), 2156(\mathrm{C} \equiv \mathrm{C}), 1257\left(\mathrm{Si}-\mathrm{CH}_{3}\right), 1028-1081$ (Si-O-Si), 784$848(\mathrm{Si}-\mathrm{C}) .{ }^{1} \mathrm{H} \mathrm{NMR}\left(\mathrm{CDCl}_{3}, \delta, \mathrm{ppm}\right) 0.38\left(\mathrm{Si}_{-} \mathrm{CH}_{3}\right), 3.07$ $(\mathrm{C} \equiv \mathrm{C}-\mathrm{H}), 7.20-7.58(\mathrm{Ar}-\mathrm{H}) .{ }^{13} \mathrm{C} \mathrm{NMR}\left(\mathrm{CDCl}_{3}, \delta, \mathrm{ppm}\right) 2.82$ $\left(\mathrm{Si}-\mathrm{CH}_{3}\right), 78.7,83.3(-\mathrm{C} \equiv \mathrm{C}-\mathrm{H}), 94.8,103.8(\mathrm{Si}-\mathrm{C} \equiv \mathrm{C}-), 123.8$, 129.0, 132.8, $136.1\left(\mathrm{C}_{6} \mathrm{H}_{4}\right) .{ }^{29} \mathrm{Si} \mathrm{NMR}\left(\mathrm{CDCl}_{3}, \delta, \mathrm{ppm}\right)-16.3$ (O-Si-C $\equiv \mathrm{C}-$ ).

The resins II-IV were prepared in a similar procedure except for using DCHMTS, DCOMTS, and DCDMHS instead of DCTMDS, respectively.

Resin II was obtained in 91\% yield as a brown viscous liquid. FTIR (KBr, cm $\left.{ }^{-1}\right) 3299(\mathrm{C} \equiv \mathrm{C}-\mathrm{H}), 3068(\mathrm{Ar}-\mathrm{H}), 2967\left(-\mathrm{CH}_{3}\right)$, $2156(\mathrm{C} \equiv \mathrm{C}), 1258\left(\mathrm{Si}_{-} \mathrm{CH}_{3}\right), 1018-1105$ (Si-O-Si), 780-847 (Si-C). ${ }^{1} \mathrm{H} \mathrm{NMR}\left(\mathrm{CDCl}_{3}, \delta, \mathrm{ppm}\right)$ 0.17-0.38 $\left(\mathrm{Si}-\mathrm{CH}_{3}\right), 3.07(\mathrm{C} \equiv \mathrm{C}-\mathrm{H})$, 7.20-7.58 (Ar-H). ${ }^{13} \mathrm{CNMR}\left(\mathrm{CDCl}_{3}, \delta, \mathrm{ppm}\right) 1.72,2.82\left(\mathrm{Si}_{-} \mathrm{CH}_{3}\right)$,

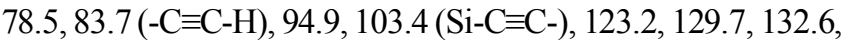
136.3 $\left(\mathrm{C}_{6} \mathrm{H}_{4}\right) .{ }^{29} \mathrm{Si} \mathrm{NMR}\left(\mathrm{CDCl}_{3}, \delta, \mathrm{ppm}\right)-16.3(\mathrm{O}-\mathrm{Si}-\mathrm{C} \equiv \mathrm{C}-)$, $-18.6 \sim-19.2$ (O-Si-O-Si-C $\equiv \mathrm{C}-)$.

Resin III was obtained in $92 \%$ yield as an orange viscous liquid. FTIR ( $\left.\mathrm{KBr}, \mathrm{cm}^{-1}\right) 3301(\mathrm{C} \equiv \mathrm{C}-\mathrm{H}), 3068(\mathrm{Ar}-\mathrm{H}), 2967$ $\left(-\mathrm{CH}_{3}\right), 2156(\mathrm{C} \equiv \mathrm{C}), 1258\left(\mathrm{Si}-\mathrm{CH}_{3}\right), 1008-1116(\mathrm{Si}-\mathrm{O}-\mathrm{Si}), 790-$ 850 (Si-C). ${ }^{1} \mathrm{H}$ NMR $\left(\mathrm{CDCl}_{3}, \delta, \mathrm{ppm}\right)$ 0.08-0.37 $\left(\mathrm{Si}_{-} \mathrm{CH}_{3}\right), 3.09$ $(\mathrm{C} \equiv \mathrm{C}-\mathrm{H}), 7.40-7.60(\mathrm{Ar}-\mathrm{H}) .{ }^{13} \mathrm{CNMR}\left(\mathrm{CDCl}_{3}, \delta, \mathrm{ppm}\right) 1.73,2.82$ $\left(\mathrm{Si}-\mathrm{CH}_{3}\right), 77.9,83.2(-\mathrm{C} \equiv \mathrm{C}-\mathrm{H}), 94.9,103.7(\mathrm{Si}-\mathrm{C} \equiv \mathrm{C}-), 123.7$, $128.9,132.7,136.2\left(\mathrm{C}_{6} \mathrm{H}_{4}\right) .{ }^{29} \mathrm{Si} \mathrm{NMR}\left(\mathrm{CDCl}_{3}, \delta, \mathrm{ppm}\right)-16.3$ (O-Si-C $\equiv \mathrm{C}-$ ), -18.6 -19.5 (O-Si-O-Si-C $\equiv \mathrm{C}-$ ) , -21.4 (O-Si-O).

Resin IV was obtained in $90 \%$ yield as an orange liquid. FTIR $\left(\mathrm{KBr}, \mathrm{cm}^{-1}\right) 3303(\mathrm{C} \equiv \mathrm{C}-\mathrm{H}), 3068(\mathrm{Ar}-\mathrm{H}), 2967\left(-\mathrm{CH}_{3}\right)$, $2156(\mathrm{C} \equiv \mathrm{C}), 1259\left(\mathrm{Si}-\mathrm{CH}_{3}\right), 1008-1130(\mathrm{Si}-\mathrm{O}-\mathrm{Si}), 775-872(\mathrm{Si}-\mathrm{C})$. ${ }^{1} \mathrm{H} \mathrm{NMR}\left(\mathrm{CDCl}_{3}, \delta, \mathrm{ppm}\right)$ 0.07-0.38 $\left(\mathrm{Si}-\mathrm{CH}_{3}\right), 3.07(\mathrm{C} \equiv \mathrm{C}-\mathrm{H})$, 7.20-7.58 (Ar-H). ${ }^{13} \mathrm{CNMR}\left(\mathrm{CDCl}_{3}, \delta, \mathrm{ppm}\right) 1.74,2.85\left(\mathrm{Si}_{-} \mathrm{CH}_{3}\right)$, 78.7, 83.6 (-C $\equiv \mathrm{C}-\mathrm{H}), 95.8,103.8(\mathrm{Si}-\mathrm{C} \equiv \mathrm{C}-)$, 123.6, 129.1, 132.6, $136.2\left(\mathrm{C}_{6} \mathrm{H}_{4}\right) .{ }^{29} \mathrm{Si} \mathrm{NMR}\left(\mathrm{CDCl}_{3}, \delta, \mathrm{ppm}\right)-16.33(\mathrm{O}-\mathrm{Si}-\mathrm{C} \equiv \mathrm{C}-)$, $-18.6 \sim-19.5(\mathrm{O}-\mathrm{Si}-\mathrm{O}-\mathrm{Si}-\mathrm{C} \equiv \mathrm{C}-),-21.4(\mathrm{O}-\mathrm{Si}-\mathrm{O})$.

Thermal curing of the resins. Prior to cure, the resins I-IV were degassed at $100{ }^{\circ} \mathrm{C} / 15 \mathrm{mmHg}$. The resins I-IV were thermally cured according to the procedure: $2 \mathrm{~h}$ at $150{ }^{\circ} \mathrm{C}, 170^{\circ} \mathrm{C}$, $210{ }^{\circ} \mathrm{C}, 250{ }^{\circ} \mathrm{C}$, and $300{ }^{\circ} \mathrm{C}$, respectively. Thereafter, the resins were allowed to cool slowly to room temperature. Shiny voidfree and dark cured resins $I_{c}-I V_{c}$ were obtained.

Thermal pyrolysis of the cured resins. The cured resins $I_{c}-I V_{c}$ were weighed in an alumina crucible and placed into tube furnace. After three purges of argon, the cured resins were heated under argon according to the procedure: $2 \mathrm{~h}$ at $400{ }^{\circ} \mathrm{C}, 600{ }^{\circ} \mathrm{C}$, $800{ }^{\circ} \mathrm{C}, 1000{ }^{\circ} \mathrm{C}, 1200{ }^{\circ} \mathrm{C}$, and $1450{ }^{\circ} \mathrm{C}$, respectively, and then cooled to room temperature. Hard and black ceramics $\mathrm{I}_{\mathrm{cc}}-\mathrm{IV}_{\mathrm{cc}}$ were obtained.

\section{Results and Discussion}

Synthesis and characterization of the resins. The synthesis reactions of arylacetylene resins with siloxane units I-IV are 


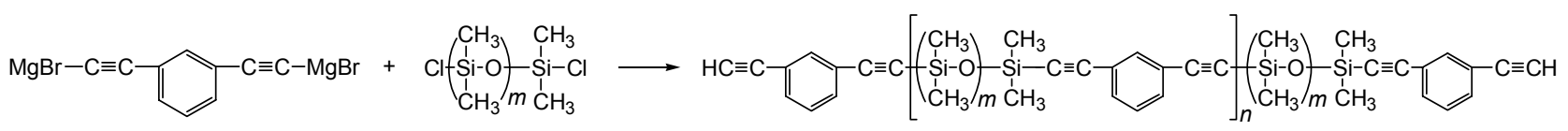

I: $m=1 ;$ II: $m=2 ;$ III: $m=3 ;$ IV: $m=5$

Scheme 1

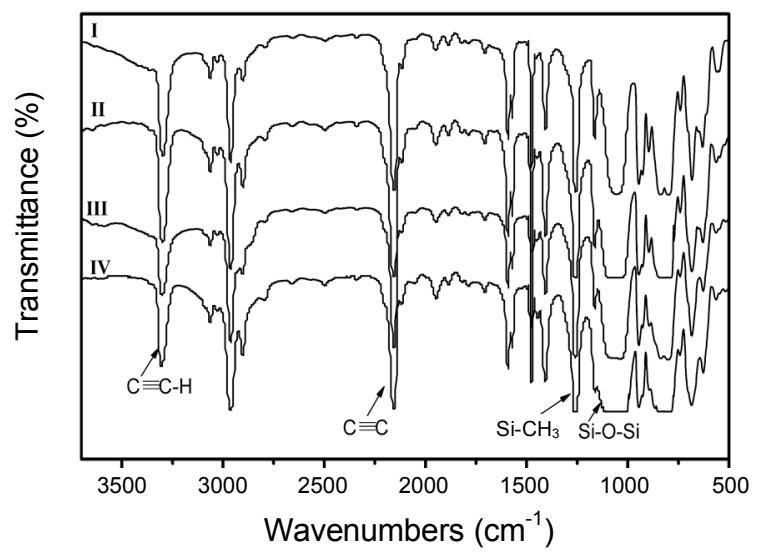

Figure 1. FT-IR spectra of the resins I-IV.

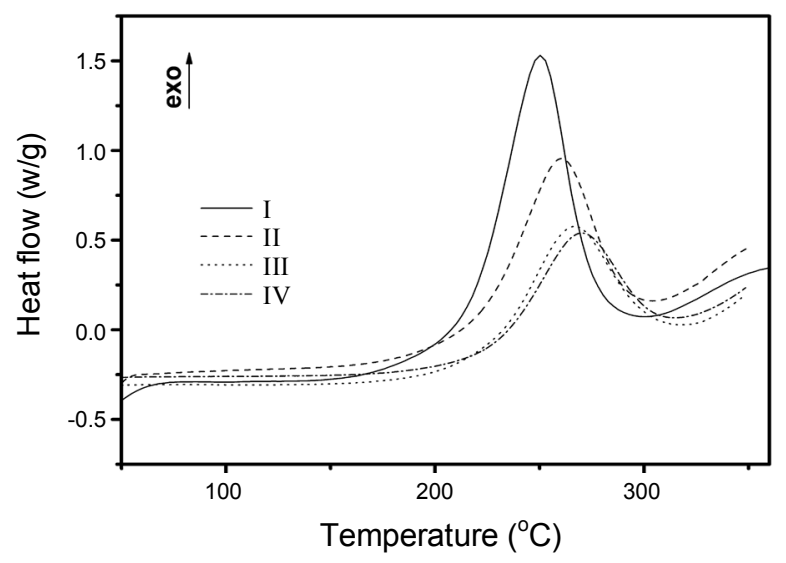

Figure 2. DSC curves of the resins I-IV.

shown in Scheme 1. The resins with various siloxane units length were synthesized by the reactions of the bismagnesium derivative of $m$-diethynylbenzene with various $\alpha, \omega$-bis(chloro)dimethylsiloxanes. The synthetic yields of the resins I-IV are higher than $92 \%$. The GPC measurement shows the resins have the number-average molecular weight between 747 and 1630, and the polydispersity index between 1.64 and 2.11.

Figure 1 shows FT-IR spectra of resins I-IV. All resins are featured by absorptions at $3300 \mathrm{~cm}^{-1}(\equiv \mathrm{C}-\mathrm{H}), 3068 \mathrm{~cm}^{-1}(\mathrm{Ar}-\mathrm{H})$, $2156 \mathrm{~cm}^{-1}(\mathrm{C} \equiv \mathrm{C}), 1258 \mathrm{~cm}^{-1}\left(\mathrm{Si}-\mathrm{CH}_{3}\right), 1008-1130 \mathrm{~cm}^{-1}(\mathrm{Si}-\mathrm{O}-$ $\mathrm{Si}$ ), and $770-850 \mathrm{~cm}^{-1}$ (Si-C). The intensity of the Si-O stretching at $1000-1100 \mathrm{~cm}^{-1}$ of the resins increases with the increase in the length of the siloxane units. As for ${ }^{1} \mathrm{H}$ NMR analysis of the resins, the dimethylsiloxy protons by peak resonances with chemical shift are observed in the $0.07-0.38$ ppm range and the protons of the terminal acetylene groups by peak resonances with chemical shift appear at $3.07 \mathrm{ppm}$. In addition, the aromatic hydrogens by peak resonances with chemical shifts resonate in the $7.20-7.58 \mathrm{ppm}$ range. The ${ }^{13} \mathrm{C}$ NMR spectrum confirms aromatic carbons by peak resonances with chemical shifts in the 123.7 - 136.1 ppm range. The internal acetylenic carbons appear as a pair of peak resonances at $94.8 \mathrm{ppm}$ and $103.8 \mathrm{ppm}$ when attached to silicon atom and aromatic ring, respectively. The terminal acetylenic carbons appear as a pair of peak resonances at $78.7 \mathrm{ppm}$ and $83.3 \mathrm{ppm}$. In addition, dimethylsiloxy carbons by peak resonances with chemical shifts are observed at 2.82 ppm. The ${ }^{29} \mathrm{Si}$ NMR resonances for each $\mathrm{Si}$ nuclei $[\mathrm{O}-\mathrm{Si}-\mathrm{C} \equiv \mathrm{C}$ at $\sim-16.3 \mathrm{ppm}, \mathrm{O}-\mathrm{Si}-\mathrm{O}-\mathrm{Si}-\mathrm{C} \equiv \mathrm{C}$ - in the range from $\sim-18.6$ ppm to $\sim-19.5$ ppm, and O-Si-O at $\sim-21.4 \mathrm{ppm}]$ appear. The characterization by ${ }^{1} \mathrm{H} \mathrm{NMR},{ }^{13} \mathrm{C} \mathrm{NMR}$ and ${ }^{29} \mathrm{Si}$ NMR confirms that the resins have the expected chemical structures as shown in Scheme 1.

Miscibility of the resins. The miscibility of the resins I-IV was investigated in various organic solvents. The resins I-IV are miscible with common organic solvents such as benzene, toluene, chloroform, THF, acetone, butanone, and dimethylformamide (DMF) at room temperature. However, the resins I-IV are immiscible in petroleum ether and methanol at room temperature. The good miscibility of the resins I-IV is probably due to the effect of the siloxane units in the main chain.

Thermal behavior of the resins. Figure 2 shows the DSC curves of the resins I-IV at a heating rate of $10{ }^{\circ} \mathrm{C} / \mathrm{min}$ in the temperature range from 100 to $350^{\circ} \mathrm{C}$ in $\mathrm{N}_{2}$. It is observed that the resins I-IV show a similar curing behavior. As shown in Figure 2, there are sharp exotherms for the resins in the temperature range from 150 to $300{ }^{\circ} \mathrm{C}$. The temperatures at peak top for the resins I-IV are $256,261,267$, and $270^{\circ} \mathrm{C}$, respectively. The enthalpies of the resins I-IV are 367.3, 225.1, 176.9 and $142.3 \mathrm{~J} / \mathrm{g}$, respectively. These exotherms are attributed to the crosslinking reaction of the ethynyl and ethynylene groups. As shown in Figure 2, the reactions take place at the temperature above $150{ }^{\circ} \mathrm{C}$. The peak temperatures top and peak width increase from the resin I to IV with the increase in the length of siloxane units. This indicates that the reactivity of the resins reduces with the increase in the length of siloxane units. Small broad exotherms in the high temperature range are also observed and are attributed to the reaction of ethynylene groups.

Themal and thermooxidative stabilities of the cured resins. The thermal stabilities of the cured resins $\mathrm{I}_{\mathrm{c}}-\mathrm{IV}_{\mathrm{c}}$ were determined by thermogravimetric analysis (TGA) in $\mathrm{N}_{2}$ and air up to $1000{ }^{\circ} \mathrm{C}$. Figure 3 shows the TGA curves of the cured resins $\mathrm{I}_{\mathrm{c}}-\mathrm{IV}_{\mathrm{c}}$ in $\mathrm{N}_{2}$ at a heating rate of $10{ }^{\circ} \mathrm{C} / \mathrm{min}$. The cured resins $\mathrm{I}_{\mathrm{c}}-\mathrm{IV}_{\mathrm{c}}$ have high onset degradation temperatures ranging from 483 to $510{ }^{\circ} \mathrm{C}$. 


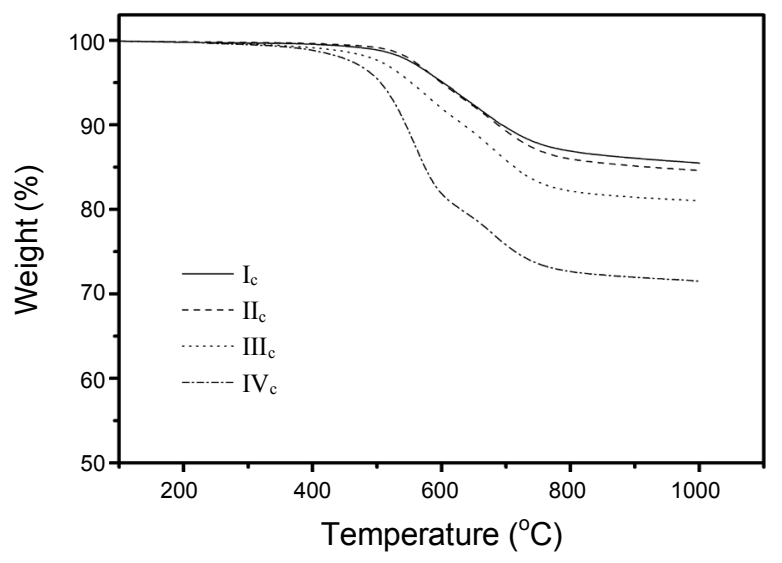

Figure 3. TGA curves of the cured resins $I_{c}-I_{c}$ in nitrogen.

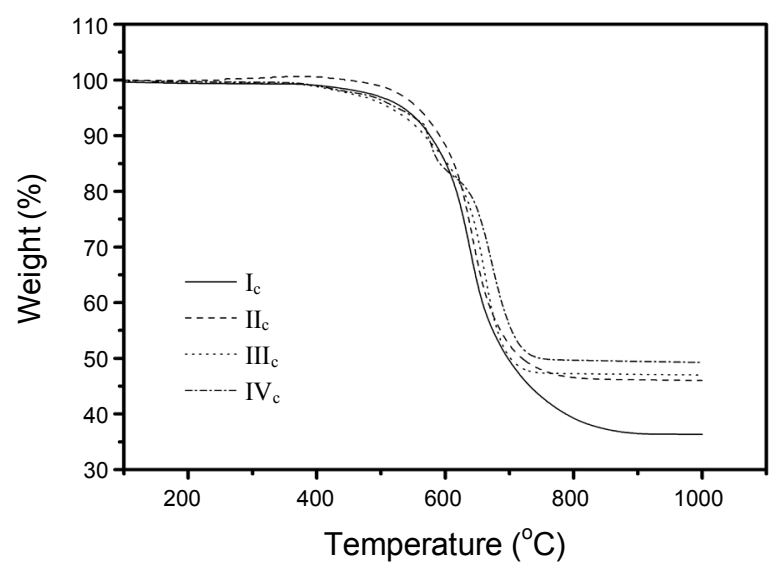

Figure 4. TGA curves of the cured resins $\mathrm{I}_{\mathrm{c}}-\mathrm{IV}_{\mathrm{c}}$ in air.

The degradation temperatures at $5 \%$ weight loss for the cured resins $\mathrm{I}_{\mathrm{c}}-\mathrm{IV}_{\mathrm{c}}$ are $602,550,532$, and $505{ }^{\circ} \mathrm{C}$, respectively. The residue yields at $1000{ }^{\circ} \mathrm{C}$ for the cured resins $\mathrm{I}_{\mathrm{c}}-\mathrm{IV}_{\mathrm{c}}$ are 86,85 , 81 , and $72 \%$, respectively. As the length of the siloxane units increases, the degradation temperatures and the residue yields at $1000{ }^{\circ} \mathrm{C}$ for the cured resins $\mathrm{I}_{\mathrm{c}}-\mathrm{IV}_{\mathrm{c}}$ decrease. This is consistent with reported trends that the increase in the siloxane units length leads to decrease the thermal stability of thermosets derived siloxane-containing polymers. ${ }^{33}$ The high thermal stability results from the highly crosslinked structures. As the length of the siloxane unit increases, the crosslinking density of the cured resins decreases. Therefore, the thermal stability of the cured resins $\mathrm{I}_{\mathrm{c}}-\mathrm{IV}_{\mathrm{c}}$ decreases with the increase in the length of siloxane units.

The thermooxidative stability of the cured resins $I_{c}-I_{c}$ were determined by thermogravimetric analysis (TGA) in air up to $1000{ }^{\circ} \mathrm{C}$. Figure 4 shows the TGA curves of the cured resins $\mathrm{I}_{\mathrm{c}}-\mathrm{IV}_{\mathrm{c}}$ in air at a heating rate of $10{ }^{\circ} \mathrm{C} / \mathrm{min}$. As expected, the stability in air is generally less than the corresponding stability in $\mathrm{N}_{2}$. The decomposition temperatures at $5 \%$ weight loss for the cured resins $\mathrm{I}_{\mathrm{c}}-\mathrm{IV}_{\mathrm{c}}$ are $548,535,522$, and $514{ }^{\circ} \mathrm{C}$, respectively. The residue yields at $1000{ }^{\circ} \mathrm{C}$ for the cured resins $\mathrm{I}_{\mathrm{c}}-\mathrm{IV}_{\mathrm{c}}$ are $36,45,47$, and $49 \%$, respectively. As the length of the siloxane units increases, the decomposition temperatures decrease whereas the residue yields at $1000{ }^{\circ} \mathrm{C}$ increase for the cured

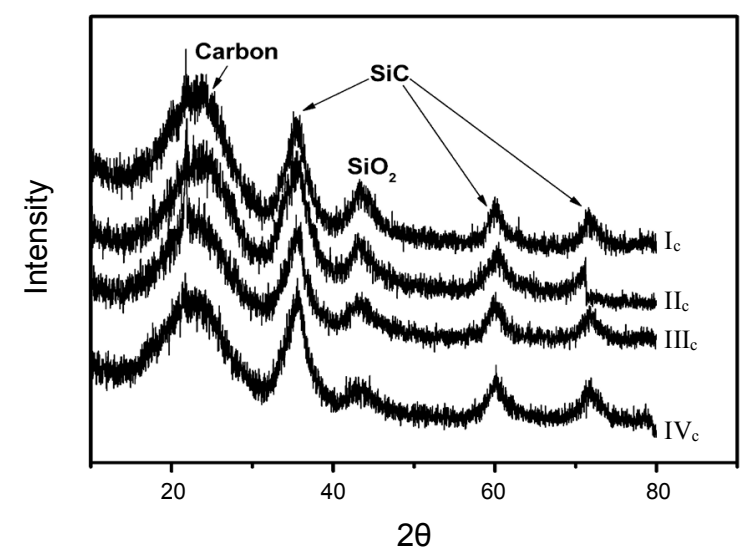

Figure 5. X-ray diffraction spectra of the ceramics $\mathrm{I}_{\mathrm{cc}}-\mathrm{IV}_{\mathrm{cc}}$.

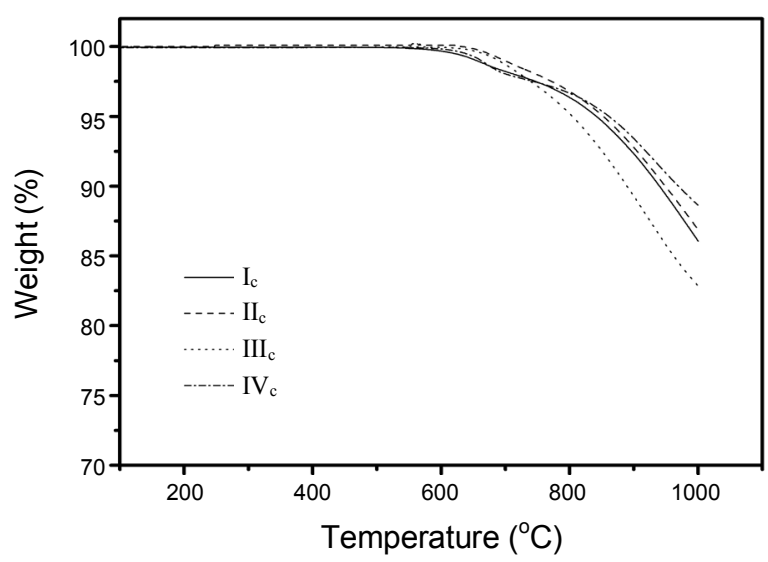

Figure 6. TGA curves of the ceramics $I_{c c}-I V_{c c}$ in air.

resins $I_{c}-I_{c}$. Unusual change in the residue yields for the cured resins $\mathrm{I}_{\mathrm{c}}-\mathrm{IV}_{\mathrm{c}}$ in air could be probably attributed to the content of siloxane units in the resins.

Characterization of the ceramics. Figure 5 shows the X-ray diffraction spectra of the ceramics $\mathrm{I}_{\mathrm{cc}}-\mathrm{IV}_{\mathrm{cc}}$ obtained from the cured resins $\mathrm{I}_{\mathrm{c}}-\mathrm{IV}_{\mathrm{c}}$ pyrolyzed at $1450{ }^{\circ} \mathrm{C}$ under argon. All the diffraction peaks have been identified and indexed on the basis of free carbon, $\beta-\mathrm{SiC}$, and $\mathrm{SiO}_{2}$. The peak at $2 \theta$ angle of 21.86 degree is attributed to free carbon. The peaks at $2 \theta$ angle of $35.54,60.42$, and 71.8 degrees are attributed to $\beta$-SiC. The peak at $2 \theta$ angle of 43.60 degree is attributed to $\mathrm{SiO}_{2}$. The ceramics $\mathrm{I}_{\mathrm{cc}}-\mathrm{IV}_{\mathrm{cc}}$ are composed of free carbon, $\beta-\mathrm{SiC}$, and $\mathrm{SiO}_{2}$. The FTIR spectra of the ceramics show two major peaks: one at 1100 $\mathrm{cm}^{-1}$ attributed to Si-O-Si stretching mode, another at about 830 $\mathrm{cm}^{-1}$ assigned to $\mathrm{Si}-\mathrm{C}$ stretching (pure crystalline $\mathrm{SiC}$ at 850 $\mathrm{cm}^{-1}$ ). The FT-IR analyses of the ceramics illustrate that $\mathrm{SiC}$ and $\mathrm{SiO}_{2}$ exist in the ceramics, which is in agreement with the XRD analysis results of these ceramics.

The thermooxidative stability of the ceramics $\mathrm{I}_{\mathrm{cc}}-\mathrm{IV}_{\mathrm{cc}}$ were determined by thermogravimetric analysis (TGA) in air up to $1000{ }^{\circ} \mathrm{C}$. Figure 6 shows the TGA curves of the ceramics $\mathrm{I}_{\mathrm{cc}}-\mathrm{IV}_{\mathrm{cc}}$ in air at the heating rate of $10{ }^{\circ} \mathrm{C} / \mathrm{min}$. As shown in the Figure 6 , there is a one-step decomposition process. The ceramics $\mathrm{I}_{\mathrm{cc}}-\mathrm{IV}_{\mathrm{cc}}$ have high onset decomposition temperatures. The decomposition temperatures at 5\% weight loss are $842,852,804$, and 
$861{ }^{\circ} \mathrm{C}$, respectively. The residue yields at $1000{ }^{\circ} \mathrm{C}$ for the ceramics $\mathrm{I}_{\mathrm{cc}}-\mathrm{IV}_{\mathrm{cc}}$ are $86,87,83$, and $89 \%$, respectively. The good thermooxidative stability for the ceramics is probably attributed to the synergistic effects of $\beta-\mathrm{SiC}$ and $\mathrm{SiO}_{2}$ in the $\mathrm{SiOC}$ ceramics.

\section{Conclusions}

A series of arylacetylene resins with various siloxane unit lengths have been synthesized and characterized. The resulted resins are liquids and miscible with common organic solvents at room temperature. These resins exhibit good processing capability. At elevated temperatures, these resins can be thermally transformed into highly crosslinked structures. TGA results show that the cured resins have high thermal and thermooxidative stability. With the increase in the length of siloxane units, the decomposition temperatures at $5 \%$ weight loss for the cured resins decrease from 602 to $505{ }^{\circ} \mathrm{C}$, and the residue yields at $1000{ }^{\circ} \mathrm{C}$ decrease from 85 to $72 \%$ in $\mathrm{N}_{2}$. By contrast, the decomposition temperatures at $5 \%$ weight loss for the cured resins decrease from 535 to $514{ }^{\circ} \mathrm{C}$, and the reside yields at $1000{ }^{\circ} \mathrm{C}$ increase from 36 to $49 \%$ in air. When these cured resins were heated above $1450{ }^{\circ} \mathrm{C}$ under argon, hard and glassy SiOC ceramics composed of $\beta-\mathrm{SiC}, \mathrm{SiO}_{2}$, and carbon were obtained. These SiOC ceramics exhibit better thermooxidative stability than the relative cured resins.

Acknowledgments. We gratefully acknowledge the financial support from the National High Technology Research and Development Program of China (Grant No.2002305205) and the National Basic Research Program of China (Grant No. 18020006).

\section{References}

1. Hay, A. S. J. Org. Chem. 1960, 25, 637.

2. Zaldivar, R. J.; Rellick, G. S.; Yang, J. M. SAMPE 1991, 27, 29.

3. Katzman, H. A.; Mallon, J. J.; Barry, W. T. J. Adv. Mater. 1995, 26, 21.

4. Itoh, M.; Mitsuzuka, M.; Iwata, K.; Inoue, K. Macromolecules 1994, 27, 7917.

5. Itoh, M.; Inoue, K.; Iwata, K.; Ishikawa, J.; Takenaka, Y. Adv. Mater. 1997, 9, 1187.

6. Itoh, M.; Inoue, K.; Iwata, K.; Mitsuzuka, M.; Kakigano, T. Macro- molecules 1997, 30, 694.

7. Itoh, M.; Iwata, K.; Ishikawa, J.; Sukawa, H.; Kimura, H. J. Polym. Sci. Part A: Polym. Chem. 2001, 39, 2658.

8. Buvat, P.; Jousse, F.; Delnaud, L.; Levassort, C. International SAMPE Symposium and Exhibition 2001, 46, 134.

9. Wang, F.; Zhang, J.; Huang, J. X.; Yan, H.; Huang, F. R.; Du, L. Polym. Bull. 2006, 56, 19.

10. Yin, G. G.; Zhang, J.; Wang, C. F.; Huang, F. R.; Du, L. e-Polymers 2008, No. 067.

11. Li, Q.; Zhou, Y.; Hang, X. D.; Deng, S. F.; Huang, F. R.; Du, L.; Li, Z. P. Eur. Polym. J. 2008, 44, 2538.

12. Zhang, L. L.; Gao, F.; Wang, C. F.; Zhang, J.; Huang, F. R.; Du, L. Chin. J. Polym. Sci. 2009, Accepted.

13. Lee, I. S.; Lee, C. G.; Kwak, Y. W.; Gal, Y. S. Bull. Korean Chem. Soc. 2009, 30, 309.

14. Zeigler, J. M.; Fearon, F. W. Silicon-Based Polymer Science: A Comprehensive Resource; ACS Symposium Series 224, American Chemical Society: Washington, DC, 1990.

15. Dvornic, P. R.; Lenz, R. W. High Temperature Siloxane Elastomers; Hüthig \& Wepf: Heidelberg, 1990.

16. Suzuki, T.; Mita, I. Eur. Polym. J. 1992, 28, 1373.

17. Son, D. Y.; Keller, T. M. Macromolecules 1995, 28, 399.

18. Son, D. Y.; Keller, T. M. J. Polym. Sci. Part A: Polym. Chem. 1995, 33, 2969.

19. Sundar, R. A.; Keller, T. M. J. Polym. Sci. Part A: Polym. Chem. 1997, 35, 2387.

20. Homrighausen, C. L.; Keller, T. M. J. Polym. Sci. Part A: Polym. Chem. 2002, 40, 1334.

21. Beckham, H. W.; Keller, T. M. J. Mater. Chem. 2002, 12, 3363.

22. Homrighausen, C. L.; Keller, T. M. Polymer 2002, 43, 2619.

23. Kolel-Veetil, M. K.; Beckham, H.; Keller, T. M. Chem. Mater. 2004, 16, 3162.

24. Kolel-Veetil, M. K.; Keller, T. M. J. Mater. Chem. 2003, 13, 1652.

25. Yamaguchi, B.; Fujisaka, T.; Okada, K. Japanese Patent 8151447, 1996.

26. Huang, F. R.; Du, L.; Wang, F.; Gao, F. Chinese Patent 1709928, 2005.

27. Mirskov, R. G.; Rakhlin, V. I.; Voronkov, M. G.; Gendin, D. V. Russ. J. Gen. Chem. 2003, 73, 165.

28. Teng, C. J.; Weber, W. P.; Cai, G. Macromolecules 2003, 36, 5126.

29. Beckmann, J.; Dakternieks, D.; Duthie, A.; Foitizik, R. C. Silicon Chem. 2003, 2, 27.

30. Yoshino, K.; Kawamata, A.; Uchida, H.; Kabe, Y. Chem. Lett. $1990,2133$.

31. Uchida, H.; Kabe, Y.; Yoshino, K.; Tsumuraya, T.; Masamune, S. J. Am. Chem. Soc. 1990, 112, 7077.

32. Ishikawa, M.; Toyoda, E.; Ishii, M.; Kunai, A.; Yamamoto, Y.; Yamamoto, M. Organometallics 1994, 13, 808.

33. Maya, E. M.; Snow, A. W.; Buckley, L. J. Macromolecules 2002 , 35,460 . 